\title{
Stimulus parameters and aggression elicited by subdermal shock in rats
}

\author{
S. D. DUNCAN and D. A. POWELL \\ Neuroscience Laboratory, VA Hospital, Columbia, South Carolina 29201 \\ and \\ University of South Carolina, Columbia, South Carolina 29208
}

\begin{abstract}
The effects of shock train duration, the intershock interval, and chamber size were studied upon the frequency of fighting elicited by subdermally administered electric shock. The 3-sec intershock interval elicited the highest rates of fighting. Shock train duration did not significantly affect fighting frequencies. At all stimulus parameter values fighting was relatively infrequent compared to footshock elicited fighting unless the fighting area was made comparable to that commonly used in grid shock experiments. When a smaller chamber was used, fighting frequencies were within the range of those obtained with footshock.
\end{abstract}

Several different subhuman models of aggression have been used to investigate aggressive behavior. The shock-aggression model as originally studied by O'Kelly and Steckle (1939) and, more recently by a variety of investigators (e.g., Thor, Ghiselli, \& Lambelet, 1974; Ulrich \& Azrin, 1962), provides a particularly good model of defensive fighting since the eliciting stimulus can be precisely controlled. However, the latter advantage is sometimes illusory, especially where the behavior is elicited by grid shock. Problems resulting from the use of grid shock have been previously discussed (Azrin \& Holz, 1966; Dinsmoor, 1961). Even when constant current shock generators and scramblers are used, inconsistent results may be obtained by changes in the animals' posture, foot placement, etc. The latter have been shown to reduce the effects of shock and to produce partial escape responses (Azrin \& Holz, 1966).

In a previous report (Duncan \& Powell, 1973), a technique was described for simultaneously presented subdermal shock to pairs of rats. This procedure eliminates many of the problems associated with footshock, since shock is presented through electrodes chronically implanted beneath the skin. However, the frequency of fighting in response to this kind of stimulation was considerably less than has been reported with footshock (Duncan and Powell, in press). The present experiment, thus, manipulated three stimulus parameters to ascertain whether these variables were related to the lowered level of fighting previously observed in response to subdermal shock. Shock intensity was investigated in a previous experiment (Duncan \& Powell, in press). Thus, the variables studied

This research was supported by VA Institutional Research Funds, Project Number 7155-01. Reprints may be obtained from the authors, Neuroscience Laboratory, Veterans Administration Hospital, Columbia, South Carolina 29201 in the present study were (a) shock duration, (b) the intershock interval, and (c) chamber size.

\section{METHOD}

Subjects

Twelve male Long-Evans hooded (Blue Spruce Farms) 100-day-old rats served as subjects. The subjects were randomly paired into six pairs and remained paired in this manner for the duration of the experiment.

\section{Apparatus}

Shock was delivered by a BRS shock generator, Model No.SGS-001. Although this shocker produces a scrambled output for connection to a grid, only four of the nine possible leads were used. Each of two leads were connected to a previously prepared animal as described by Campbell and Moorcroft (1970). The test chamber is described by Duncan and Powell (1973). Briefly, it consisted of an $18 \times 36 \times 23$ in. $(45.72 \times 91.44 \times 58.42 \mathrm{~cm})$ plywood box with a Plexiglas front for observation of the animals. Partitions could be placed in each end to decrease the available fighting space, if desired. In the present experiment, except when experimental space was studied, these partitions were placed $1 / 4$ of the distance from the center of the chamber so that the experimental space comprised an $18 \times 18$ in. $(45.72 \times 45.72 \mathrm{~cm})$ square area. A commutator and swivel arrangement similar to that described by Atrens and Mendelson (1970) was mounted in each of two diagonally opposite corners at the top of this area. Shock leads were routed to the animals through these commutators. To prevent the leads from becoming twisted or entangled, their length from the commutator to the subject was carefully adjusted. Thus, the pair of rats were allowed to meet in the center or a "neutral" corner of the chamber for social interaction, but could not get in back of each other and become entangled in the other's leads. This arrangement allowed the rats limited freedom of movement in all three dimensions. Implantation of silver ring electrodes (Narco-Biosystems, Houston, Texas) in the hide over the gluteus maximus muscle was also described by Duncan and Powell (1973).

\section{Procedure}

All rats were implanted with electrodes and allowed to recover for 7 days. Subsequent sessions were used to study the effects of (a) shock frequency, (b) shock duration, and (c) chamber size. 


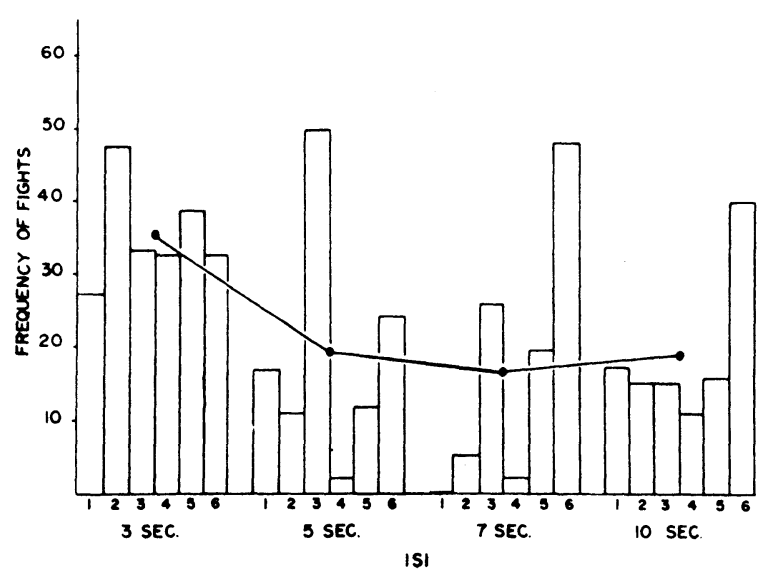

Figure 1. Frequency of fighting observed as a function of different intervals of shock presentation. Mean fighting frequency is superimposed upon scores of individual pairs of rats.

In order to study shock frequency, 3-, 5-, 7-, and 10-sec intertrial intervals were employed over four successive daily sessions. One hundred $.5-\mathrm{sec} 2-\mathrm{mA}$ shocks were administered during all four sessions, and the order in which shock frequencies were administered was randomly determined. Four further sessions were employed during which .1-, .3-, .5-, and .7-sec shock durations were studied. Again, 100 shocks were administered per daily session with the order of durations randomly determined across sessions. Shock frequency was 20 shocks/minute at an intensity of $2 \mathrm{~mA}$. Finally, three different chamber sizes were employed over three successive subsequent sessions in which 100-2 mA, .5-sec shocks were delivered at a frequency of 20 shocks/minute. The area of the chambers during these sessions was (a) $45.7 \times 91.4 \times 58.4 \mathrm{~cm} \mathrm{(4176} \mathrm{sq.} \mathrm{cm),}$ (b) $45.7 \times 45.7 \times 58.4 \mathrm{~cm}(2088 \mathrm{sq} . \mathrm{cm})$, and (c) $30.5 \times 23 \times 23 \mathrm{~cm}$ (707 sq. cm).

A trial was defined as the occurrence of a shock, and only the occurrence or nonoccurrence of a response (viz., response frequency) was recorded for each trial. Fighting was defined as (a) the mutually upright posture with or without striking behavior, (b) dominance-submission postures, or (c) biting behavior. The behavior of each pair of animals was recorded by each of two observers who were "blind" with respect to the shock conditions observed. Agreement between the two observers was consistently greater than $90 \%$ and averaged $93 \%$ over all conditions.

\section{RESULTS}

Figures 1-3 show fighting frequency (for only a single observer) as a function of each of the three variables studied in the present experiment. Average fighting frequency is shown superimposed upon individual scores. As can be seen in Figure 1, intershock intervals greater than 3 -sec resulted in relative decrements in fighting, a finding also reported by Ulrich and Azrin (1962) with regard to grid shock. As can be seen in Figure 2, increasing the shock duration resulted in higher fighting frequency scores up to .5 -sec, which was the optimum duration reported by Azrin and colleagues (Azrin, Ulrich, Hutchinson, \& Norman, 1964) in the grid shock situation. Moreover, increasing the duration further to .7-sec did not result in higher fighting frequencies. Instead a slight decrement occurred. This .7-sec duration, as well as longer durations used with pilot animals, resulted in a crouching type behavior which appeared to interfere with the stereotyped upright posture elicited by shock and consequently decreased fighting frequencies. Analysis of variance of these data revealed that the differences related to shock frequency were significant $(F=3.80), p<.05)$, but those related to shock duration were not. However, this latter insignificant effect was probably due to the one aberrant pair of animals (No.5 in Figure 2) in the .1-sec condition which showed an extremely high rate of aggression.

As can be seen in Figure 3, experimental space also affected fighting frequencies. The smallest space was identical in area to some of the grid-shock chambers commonly used for shock-aggression experiments (e.g., Scientific Prototype). When this size chamber was employed, fighting scores as high as 70 and 80 fights per session were obtained. Although these response frequencies are less than the maximum 90\%-100\% fighting scores obtained with some animals when grid shock is employed (Powell, Francis, Braman, \& Schneiderman, 1969), they are within the range of the latter scores. Of further interest is the finding that larger chamber sizes resulted in smaller fighting frequencies, as might be expected from the prior results of Ulrich and Azrin (1962) with grid shock. Analysis of variance revealed these differences to be significant $(F=15.5$, df $=2 / 15, \mathrm{p}<.001$ ).

\section{DISCUSSION}

The results of the present experiment confirm those of a previous study of fighting in response to subdermal shock

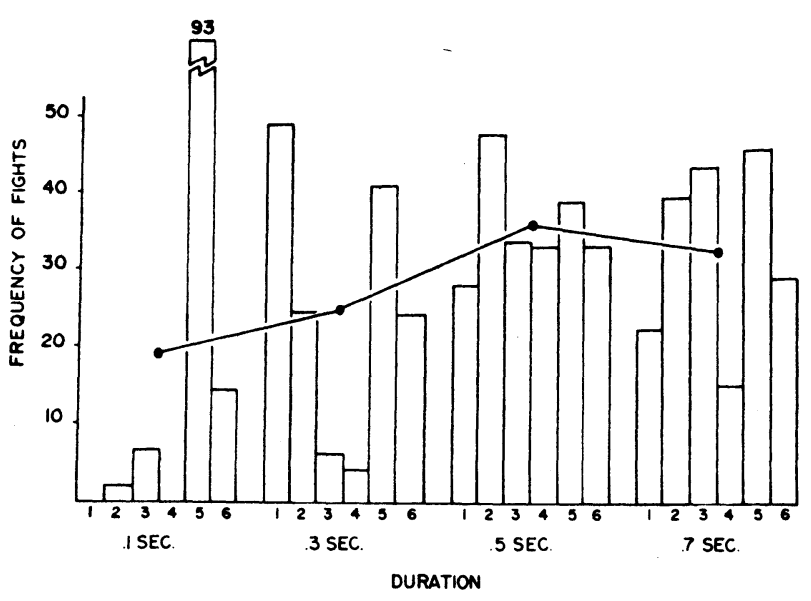

Figure 2. Frequency of fighting observed as a function of different shock durations. Mean fighting frequency is superimposed upon scores of individual pairs of rats. 
(Duncan \& Powell, in press) in that reliable rates of fighting occurred over sessions in individual pairs of animals. Moreover, the present data also indicate that aggression is systematically related to the stimulus parameters of this situation. Duncan and Powell (in press) found that shock intensity was a curvilinear function of aggression elicited by subdermal shock, with $2 \mathrm{~mA}$ eliciting the highest fighting rates in Long-Evans rats. However, even these frequencies were moderate to low (approximately $35 \%$ ) compared to the relatively high rates of aggression elicited by footshock $(80 \%-100 \%)$. In the present experiment, it was found that if a chamber of comparable floor area to that commonly used in grid shock experiments were used, higher frequencies of fighting were obtained in all animals. Although shock frequency and duration were systematically related to response frequency, substantial increases in fighting were not obtained until chamber size was dramatically decreased.

Although individual agonistic postures were not recorded in the present study, it was observed that many of the aggressive postures commonly seen in rodents (Grant \& Mckintosh, 1963) occurred in response to subdermal shock. The mutually upright posture with striking blows by both animals was the most frequent response. However, biting, threat, dominance-submission, and the sideways attack posture were also observed. Since shock in the present study was inescapable, these findings suggest that the fighting response to footshock is not an attempted escape response as has been previously suggested (Johnson, 1972). Rather, painful stimuli appear to elicit a wide range of agnonistic postures that appear to be identical to those observed in more natural situations.

\section{REFERENCES}

Atrens, D. M., \& Mendelson, J. An inexpensive swivel device for the delivery of brain stimulation to unstrained animals. Physiology and Behavior, 1970, 5, 707-708.

Azrin, N. H., \& Holz, W. C. Punishment. In W. K. Honig (Ed.), Operant Behavior. Areas of research and application. New York: Appleton-Century-Crofts, 1966. Pp. 380-477.

Azrin, N. H., Ulrich, R. E., Hutchinson, R. R., \& Norman, D. G. Effects of shock duration on shock induced tighting. Journal of the Experimental Analy sis of Behavior, 1964, 7, 9-11.

Campbell, B. A., \& Moorcroft, W. H. Relative aversiveness of subcutaneous shock and footshock in the rat. Behavior Research Methods and Instrumentation, 1970, 2, 222-224.

Dinsmoor, J. A. A wide range constant current shock stimulator.

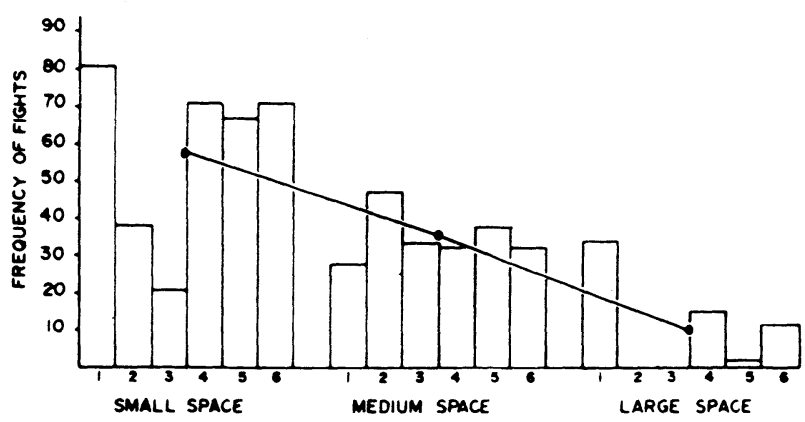

Figure 3. Frequency of fighting observed as a function of chamber size. Total areas were for (a) small chamber-707 sq cm, (b) medium chamber-2088 sq cm., and (C) la rge chamber-4176 sq cm. Mean fighting frequency is superimposed upon scores of individual pairs of rats.

Journal of the Experimental Analysis of Behavior, 1961, 4, 273-274

Duncan, S. D., \& Powell, D. A An inexpensive apparatus for presenting aversive stimulation to rodents in a social situation. Psychological Reports, 1973, 32, 851-854.

Duncan, S. D. \& Powell, D. A. Agonistic behavior elicited by subdermal shock in rats. Psychological Reports, in press.

Grant, E. C., \& McKintosh, J. H. A comparison of the social postures of some common laboratory rodents. Behavior $1963,21,246-259$.

Johnson, R. N. Aggression in man and animals. Philadelphia: Saunders, 1972.

O'Kelly, L. I., \& Steckle, L. C. A note on longenduring emotional responses in the rat. Journal of Psychology, 1939, 8, 125-131.

Powell, D. A. Francis, J., Braman, M. T., \& Schneiderman, N. E. Frequency of attach in shock elicited aggression as a function of the performance of individual rats. Journal of the Experimental Analy sis of Behavior, 1969, 12, 817-823.

Thor, D. H.. Ghiselli, W. B., \& Lambelet, D. C. Sensory control of shock-elicited fighting in rats. Physiology and Behavior, $1974,13,683-686$.

Ulrich, R. E., \& Azrin, N. H. Reflexive fighting in response to aversive stimulation. Journal of the Experimental Analysis of Behavior, 1962, 5, 511-520.

(Received for publication January 13, 1975.) 